\title{
Public Health in Pennsylvania
}

\author{
BY. BERWYN F. MATTISON, M.D.
}

$\mathrm{O}$ UR changing attack on disease is necessitated by changing community disease patterns. To provide new and extended forms of health protection for the people of Pennsylvania, we have asked for support of services of proved efficacy and for limited demonstrations to provide effective health protection techniques where none are now available. Without that support, the people will die needlessly.

\section{A Purchasable Commodity}

It has been said that "public health is purchasable," and that statement is still true. If those who might be tempted to "economize" on health could but know the human details of the resultant personal misery, they would hesitate no longer. This understanding is no matter for statistics. Even words are inadequate!

To appreciate the real value of what we do in public health one must experience the moments of anguish, as so many physicians and nurses present today have, when a mother is told that her tiny daughter, born a few hours or days prematurely, has not survived-and know, within his heart, that with very special care,

Dr. Mattison, secretary of health of the Commonwealth of Pennsylvania, presented this paper at Pennsylvania's Fourth Annual Health Conference, held August 16, 1955, at University Park, Pa. In Pennsylvania, the health conference pattern provides for full participation of four autonomous groups: the Pennsylvania Department of Health, the Health Council, the Medical Society, and the Public Health Association. she might have lived. Or, one must have had the responsibility of telling parents that their apparently healthy boy has epilepsy and feel keenly that much could be done for him that may never be done.

I have seen an otherwise attractive little 9year-old girl hiding behind a packing box and peering wistfully out at other children because her unrepaired harelip was a thing of laughter and ridicule among them. Yet, Pennsylvania has one of the best programs in the Nation for that kind of care. I have looked into the eyes of a still feverish child who was running and playing a week ago and evaded the answer to her unspoken question as she tried to move a leg made limp by poliomyelitis and wondered if our present local health services are geared to assure every child in the State the new protection available.

How many of us have cared for cancer patients-heard them tell of their families and their plans for the future-when we knew full well that, through lack of information, or diagnostic facilities, or willingness to accept early treatment, they had already traded a probable cure for certain tragedy? Not only statistics but a sense of personal values should indicate universal support for our programs.

The estimated number of Pennsylvanians suffering from chronic alcoholism is staggering. The dollar loss to industry, year after year, is appalling. But the real enormity of the problem only hits us when we think of our friend and neighbor, Joe Doaks, who had a good job, a home, and a happy marriage with two fine children. Before help was provided, he had lost his job, his home, and the respect of his wife and children. The look in those children's 
eyes, the tone of their voice when they mention their father-these are not statistics. They transcend cold, hard facts and figures.

The young man who didn't complete his schooling because, a generation ago, his father died of tuberculosis has finally worked up to a decent job, has married and had his first boy, and is now told that he, too, has tuberculosis. But, it is early and minimal, because it was picked up by a mass survey before he became ill. A fine hospital with excellent medical care is freely available to him. A public health nurse will help his physician check his family and will help carry out a home care regimen prescribed by his physician after a shortened hospital stay. We know, and he knows, that his chances of returning to his family and his job within a reasonable length of time are excellent.

These are the human values we are dealing with day in and day out. Let us not move so far away from them that we, or any one else, will be allowed to think of public health only in terms of statistics or dollars.

\section{Applied Principles}

The principles we are applying in a steppedup program of health protection for Pennsylvania are many.

First, we accept the fact that optimum communitywide prevention of disease is not a oneman or a one-agency affair. Three links are needed to forge the chain, each one equally vital : the individual, who must be given the knowledge of, and willingness to accept, what modern medicine can offer him; the private physician, the first line of defense against many diseases, who should provide community leadership in all health programs; and the health agencies, official and voluntary, which can do those things not possible individually but effective on a group or community basis. It has been used so much that I hesitate to label public health a "team" affair. But, with the complexity of our social and industrial structure and with the variety and costliness of health protective techniques now available, it most certainly requires the best efforts of all-working together as closely as we can-to do the most nearly complete job.
Second, we have accepted the increasingly important role played by health education in today's public health practice. Health education stands in the same paramount position now as sanitation did 50 years ago. It presents our best weapon against the chronic diseases now most prevalent, just as sanitary measures provide a continuing bulwark against the gastrointestinal diseases.

Our task is not simple, for information is not enough. We must learn how to break down "sins" which beset us all-lethargy, rationalization, and misinformation. Probably no area of discussion, not even the weather, has been so long and thoroughly explored as our physical and emotional ills. Yet we have on]y to consider the folklore which has been built up around one disease, poliomyelitis, to highlight our difficulty. Much misinformation must be dispelled, much wishful thinking replaced by openmindedness, before we can begin to arouse folks from their complacency and stimulate useful action. This will take time, training, and tenacity.

Third, we accept the proposition now repeatedly proved across the land that health services as nearly indigenous as possible are the most effective. Pennsylvania has, and always should have, broad responsibilities to see that the health of its people is protected. It will probably always be far more economical and efficient to have a central staff of experts in the various health fields to prepare standards and devise general programs.

But only as counties and health districts begin to participate in both supporting and providing the services they need to protect their health will those services be best tailored to each community's needs and be best accepted by its residents.

Only two counties have used the 1951 permissive legislation to establish local health departments. Many more are seriously exploring the possibility. What do county departments of health offer these areas now considering this extension of health protection? They offer more local determination of service priorities based on greater sensitivity to local needs; qualified medical leadership in public health, which in turn means closer coordination with 
the clinical practitioners and increased interest on their part in preventive medicine; a broader tax base for the support of health services; and more readily available local services, whether they be nursing, immunization, sanitation, or health education.

As county departments spread across the State, many of the direct service functions now provided out of Harrisburg can be cut down proportionately. Supervision and correlation will, of course, be continued through district and regional offices.

Fourth, we accept the need for continually evaluating our programs. This is not easy, and we are inclined to give the concept lipservice rather than to work out real evaluations. There are at least three levels on which a program can be tested for its worth: the degree to which it meets a short-range, immediate objective such as reduction in complaints after correction of an overflowing septic tank; or the degree to which the program complies with established standards of acceptable performance such as the percentage of employees in a department having permanent merit system status; or finally, the degree to which a program can be associated in a cause and effect relationship with decreased morbidity and mortality rates. But whether our program tests are at the proximate, intermediate, or ultimate levels, some tests must be made, and year by year they must be improved. One of the immediate tests we might apply is to check our services against the health indexes of the people served.

We can observe vast differences in these health indexes. For example, our best 3 cities, as far as infant deaths are concerned, have an average infant death rate of 3.1 per 1,000 live births, but our poorest 3 cities have an average death rate of 14.6. This means that for every 15 baby deaths in one kind of community the other community has only 3. Are we putting in proportionately greater efforts to reduce the latter toll? Our best 5 cities have an average tuberculosis death rate of 2.6 per 100,000 population, but in our worst 5 cities we have an average rate of 20.3. So, for every 20 tuberculosis deaths in one kind of community there are less than 3 in the other. Our intensified efforts should be focused on the area with the greater need.

With these principles in mind, teamwork, health education, local autonomy, and evaluation; with adequate inancial support from our appropriating bodies; and with the continued selfless dedication to the cause of better community health on the part of every one of us, we will together decrease each year the number of those among us who have been dying needlessly.

\section{Mental Health Admissions}

There were more than twice as many first admissions as discharges at public mental hospitals in 1954, according to the National Institute of Mental Health, Public Health Service.

New cases numbered 12,485 , or 8 per 100,000 population, while 5,815 patients were discharged and 1,026 readmitted. The average daily patient load, including epileptics as well as mental cases, was 138,595, with 109,931 classed as mental defectives. The range of expenditures for patient care varied considerably among the States, but the average cost per patient-year was $\$ 1,039$. Of the 157,770 patients on the hospital books at the end of the year, 139,977 were listed as in residence.

Data compiled by the National Institute of Mental Health for 1955 will appear in the forthcoming issue of Public Health Reports. 